\title{
PPS 20 - Polymer Processing Society Annual Meeting
}

O evento Polymer Processing Society (PPS) 2004 Annual Meeting and $20^{\text {th }}$ Anniversay Celebration foi realizado entre os dias 20 e 24/06/2004 no hotel Crowne Plaza Quaker Square na cidade de Akron, OH, EUA. O PPS 20 se iniciou com uma cerimônia de abertura no dia 20/06/2004. Deve ser destacado que o PPS 20 marcou a comemoração de 20 anos de existência da Polymer Processing Society - PPS. Maiores informações sobre a PPS podem ser encontradas no site http://Www.poly-eng.uakron.edu/PPS. O evento recebeu mais de 400 trabalhos inscritos e reuniu aproximadamente 300 participantes de vários lugares do mundo. O programa do evento foi baseado em 6 sessões orais paralelas (simultâneas) diárias e uma sessão de pôster. As sessões orais eram geralmente iniciadas através de uma palestra principal plenária, ministrada por algum pesquisador de renome na área de processamento de polímeros. Durante o evento foram realizadas atividades sociais de confraternização e uma sessão plenária (assembléia) para os sócios da PPS. Deve ser ressaltada a homenagem prestada ao Prof. Dr. James L. White, pesquisador que dedicou sua vida à área de processamento de polímeros e foi o fundador da PPS.
Dentre os simpósios, os mais concorridos foram o de Polymer Nanotechnology, Composites, Blending \& Compounding e Molding Technology. Deve ser ressaltado que os tópicos sobre nanocompósitos poliméricos foram os mais procurados entre as palestras e trabalhos apresentados. Devem ser também destacadas as palestras principais (plenárias) tais como aquelas proferidas pelos doutores C. D. Han(nanocompósitos), C. W. Makosco (compatibilização em blendas), C. B. Bucknall (tenacificação de plásticos), A. J. Epstein (polímeros condutores elétricos) e J. M. White (perspectivas em processamento de polímeros). Enfim, o evento proporcionou a reunião de vários especialistas e pesquisadores famosos na área de processamento de polímeros.

O Brasil esteve representado pelo Prof. Elias Hage Junior (DEMa/UFSCar) que é o Coordenador (Chairman) do evento PPS 2004 Americas Regional Meeting que será realizado entre 07 e 10 de novembro de 2004, em Florianópolis, Santa Catarina. O Prof. Elias aproveitou a oportunidade para divulgar o referido evento e para convidar diversos especialistas em trans-

\begin{tabular}{lll}
\hline & \multicolumn{1}{c}{ Simpósio PPS } & \\
\hline Adhesion \& Adhesives & Foam Technology & Process Monitoring \& Control \\
Blending \& Compounding & Frontier Processing Technology & Radiation Processing \\
Composites & $\begin{array}{l}\text { Green Materials \& Processing } \\
\text { Technology }\end{array}$ & Reactive Processing \\
Conductive Polymers \& Electro-optics & Modeling \& Simulation & Rheology \& Rheometry \\
Extrusion Technology & Molding Technology & Rubber Performance \\
Fibers \& Films & Polymer Nanotechnology & Rubber Processing \\
Structure Developing in Polymer Processing & & \\
\hline
\end{tabular}

O congresso foi organizado na forma de simpósios onde cada um versava sobre um tema na área de processamento de polímeros. 19 simpósios foram apresentados em sessões orais programadas durante o evento. O quadro apresentado acima mostra os temas dos simpósios. formação de polímeros para participarem do evento regional da PPS que será realizado pela primeira vez na América Latina. Maiores informações sobre o PPS 2004 podem ser encontradas no site http://marte.nit.ufscar.br/ pps2004/index1.php.

Prof. Elias Hage Jr., Departamento de Engenharia de Materiais, Universidade Federal de São Carlos. 

